A N N A L E S

UNIVERSITATIS M A R I A E C URIE-SKŁODOW S K A

LUBLIN - POLONIA

VOL. LXXII

SECTIO F

2017

Christian-Albrechts-Universität, Kiel

OLIVER AUGE

oauge@email.uni-kiel.de

\title{
Hansestädte im Ostseeraum zwischen Autonomie und Landesherrschaft
}

Miasta hanzeatyckie pomiędzy autonomią a władzą panów ziemskich

\section{ZUSAMMENFASSUNG}

Das Magdeburger Stadtrecht hatte bekanntlich einen enormen Einfluss auf die Genese und Ausbildung der Stadtrechte und damit auch auf die Stadtentwicklung in Ostmittel- und Osteuropa. Die zweite große Stadtrechtsfamilie, die bis weit nach Osteuropa hinein prägend für die Urbanisierung und autonomiebegründend werden sollte, ist diejenige des Lübischen Rechts. Über 100 Städte, darunter Reval und auch Novgorod, werden dieser Stadtrechtsfamilie zugeordnet, die sich schwerpunktmäßig über den südlichen Ostseeraum und die angrenzenden Regionen erstreckte. Ein Großteil der betreffenden Städte verstand sich auf Dauer oder zumindest zeitweilig zugleich als Hansestädte. Um deren Ringen zwischen Autonomie und Landesherrschaft geht es in diesem Beitrag. Zu diesem Zweck wird zunächst die allgemeine Forschungssituation skizziert, um auf dieser Grundlage die Genese der städtischen Autonomie Lübecks im Spannungsfeld verschiedener miteinander konkurrierender Stadtherren bis 1226 zu entwickeln. Darauf wird am Beispiel der Stadt Kiel gezeigt, mit welchem wechselnden Erfolg andere Städte dem Lübecker Vorbild zu folgen versuchten. In einem weiteren, abschließenden Schritt wird dargelegt, wie sich die Hansestädte insgesamt gegen den zum Ausgang des späten Mittelalters wachsenden Territorialisierungsdruck der Fürsten und Landesherren auf dem Wege einer verstärkten Bündnispolitik zur Wehr zu setzen bemühten. Von einem Ende der Autonomie dieser Städte kann trotz des letztlichen Scheiterns dieser Bündnisbemühungen nicht gesprochen werden. Diese verloren die Städte erst im Zeitalter des Absolutismus.

Schlüsselwörter: Lübisches Recht; Bestfreiheit; Lübeck; Autonomie; Kiel; Landesherrschaft; Tohopesate; Hansetag; Bündnispolitik; Vierstädtegericht; Absolutismus

Die Tagung zur 700-Jahrfeier der Stadt Lublin 2017, deren Beiträge in diesem Band der „Annales UMCS. Sectio F“ versammelt sind, nahm schwerpunktmäßig das Thema der städtischen Autonomie und Selbstverwaltung im Mittelalter in den Blick. 
Das Magdeburger Stadtrecht hatte bekanntlich einen enormen Einfluss auf die Genese und Ausbildung der Stadtrechte und damit auch auf die Stadtentwicklung in Ostmittel- und Osteuropa ${ }^{1}$. Wieland Carls, Caspar Ehlers oder Katalin Gönczi führen das in ihren, ebenfalls in diesem Band abgedruckten Beiträgen nochmals anschaulich vor Augen ${ }^{2}$. Die zweite große Stadtrechtsfamilie, die bis weit nach Osteuropa hinein prägend für die Urbanisierung und autonomiebegründend werden sollte, ist diejenige des Lübischen Rechts ${ }^{3}$. Über 100 Städte, darunter Reval und auch Novgorod, werden dieser Stadtrechtsfamilie zugeordnet, die sich schwerpunktmäßig über den südlichen Ostseeraum und die angrenzenden Regionen erstreckte. Ein Großteil der betreffenden Städte verstand sich auf Dauer oder zumindest zeitweilig zugleich als Hansestädte. Um deren Ringen zwischen Autonomie und Landesherrschaft soll es im folgenden Beitrag gehen. Das macht im Gesamtkontext dieser Veröffentlichung der Lubliner Tagungsbeiträge vor allem deswegen Sinn, weil man auf diese Weise ein aussagekräftiges, da auf einer zahlenmäßig breiten Basis stehendes Vergleichsmodell zur Lubliner Stadtrechtsverleihung von 1317 erhält, wodurch man letztlich erst deren Besonderheiten oder Allgemeinplätze vollends festzulegen vermag.

Über die Autonomie der Hansestädte wurde schon lange nicht mehr schwerpunktmäßig geforscht, was angesichts der Relevanz des Themas auf den ersten Blick verwundern muss. Denn abschließend untersucht ist das Phänomen beileibe noch nicht, wie ein nahezu beliebig ausgewähltes Beispiel verdeutlichen kann: Gemeinhin wird in der Hanseforschung davon ausgegangen, dass der Entzug des Willkürrechts und das Verbot von Städtebündnissen, auch das Fehlen eines „vollmächtigen Rats“ - alles wesentliche Bestandteile dessen, was man unter Autonomie als Sammelbegriff subsumiert - grundsätzlich zum Verlust der Hansefähigkeit einer Stadt geführt hätten ${ }^{4}$. Steffen Langusch freilich hinterfragte in einem Aufsatz von 2015 am Beispiel Salzwedels die grundsätzliche Richtigkeit dieser verbreiteten Ansicht. Denn seiner Meinung nach bestand zwischen den Salzwedeler Sühnebestimmungen von 1488, die die politische Selbstständigkeit

1 Vgl. dazu z.B. Grundlagen für ein neues Europa. Das Magdeburger und Lübecker Recht in Spätmittelalter und Früher Neuzeit, hrsg. v. H. Lück, M. Puhle, A. Ranft, Köln u.a. 2009.

2 W. Carls, Zur Praxis des Sächsisch-Magdeburgischen Rechts in Polen; C. Ehlers, Räumlichkeit des Magdeburger Rechts; K. Gönczi, Die Idee moderner Kommunalverfassungen und das Magdeburger Recht im östlichen Europa.

3 W. Ebel, Lübisches Recht, Bd. 1, Lübeck 1971; L. Weyhe, s.v. Lübisches Recht, [in:] Lexikon des Mittelalters V, ND München 2002, Sp. 2150f.; K. Kroeschell, s.v. Stadtrecht, Stadtrechtsfamilien, [in:] Lexikon des Mittelalters VIII, ND München 2002, Sp. 24-26, hier Sp. 25. Auch zum Folgenden.

4 Siehe dazu etwa M. Puhle, Das politische System der Hansestädte, [in:] Die Hanse, hrsg. v. R. Hammel-Kiesow, M. Puhle, S. Wittenburg, Darmstadt 2009, S. 74-83, hier S. 80. 
der Stadt stark beschnitten, und dem offiziellen Ende der Hansemitgliedschaft 1518, also 30 Jahre später, kein unmittelbarer Zusammenhang ${ }^{5}$.

Die Autonomie der Hansestädte wurde im größeren Zusammenhang letztmals explizit in Magdeburg im Oktober 1980 auf der 25. Jahrestagung der Hansischen Arbeitsgemeinschaft der DDR zum Thema gemacht. Das verwundert nicht, galten Karl Marx die „souveränen“ Städte des Mittelalters doch als „Glanzpunkt" jener Epoche $^{6}$. Die Publikation der entsprechenden Referate erfolgte 1984 als Band VI der Hansischen Studien ${ }^{7}$. Namhafte Historiker der DDR wie Eckhard Müller-Mertens ${ }^{8}$, Horst Wernicke ${ }^{9}$, Evamaria Enge ${ }^{10}$, Konrad Fritze ${ }^{11}$ oder Heidelore Böcker $^{12}$, aber auch Benedykt Zientara aus Warschau ${ }^{13}$ oder P.H.J. van der Laan aus Amsterdam ${ }^{14}$ äußerten sich darin zur städtischen Autonomie während der Hansezeit. Es ist bekannt, dass die Hanseforschung zur DDR-Zeit in ihrer gewissen mediävistischen,NNischenexistenz“, bezogen wohlgemerktaufihreInhalteundnicht aufihren damaligen Stellenwert, vergleichsweise wenig bis gar keinen sozialistischideologischen Ballast mit sich führte. Das zeigt sich markant z.B. daran, dass sich die DDR-Hanseforschung gar nicht davor scheute, den von Belastungen der NS-Zeit alles andere als unbeschwerten Altmeister der Hansegeschichte Fritz Rörig als einen ihrer Wegbereiter zu bezeichnen ${ }^{15}$. Neben der sozialistischen Generalthese, „dass dem Städtewesen und den Städtebünden eine fortschrittliche Rolle bei der Überwindung des vollentfalteten Feudalismus zugekommen sei“, diese These liefert sogleich auch den Grund dafür, dass man sich in der DDR für das Thema städtischer Autonomie interessierte - beschränkten sich die Bezüge

5 S. Langusch, Salzwedel und die Hanse, „Jahresbericht des altmärkischen Vereins“ 2015, Bd. 85, S. 1-39, hier S. 17 f.

6 K. Marx, Das Kapital, Bd. 1, Berlin 1971, S. 743.

7 Autonomie, Wirtschaft und Kultur der Hansestädte. Johannes Schildhauer zum 65. Geburtstag, hrsg. v. K. Fritze, E. Müller-Mertens, W. Stark, Weimar 1984.

8 E. Müller-Mertens, Bürgerlich-städtische Autonomie in der Feudalgesellschaft. Begriff und geschichtliche Bedeutung, [in:] Autonomie, Wirtschaft und Kultur der Hansestädte..., S. 11-34.

9 H. Wernicke, Die Stadt in der Städtehanse. Zwischen städtischer Autonomie und bündischer Pflichterfüllung, [in:] Autonomie, Wirtschaft und Kultur der Hansestädte..., S. 35-44.

10 E. Engel, Zur Autonomie brandenburgischer Hansestädte im Mittelalter, [in:] Autonomie, Wirtschaft und Kultur der Hansestädte..., S. 45-75.

${ }^{11}$ K. Fritze, Autonomie von Mittel- und Kleinstädten. Dargestellt am Beispiel der mittelalterlichen Kleinstädte Vorpommerns, [in:] Autonomie, Wirtschaft und Kultur der Hansestädte..., S. 76-83.

${ }^{12} \mathrm{H}$. Böcker, Autonome Rechte und Entwicklungsfaktoren in Haldensleben bis zum Ende des 15. Jahrhunderts, [in:] Autonomie, Wirtschaft und Kultur der Hansestädte..., S. 84-93.

${ }^{13}$ B. Zientara, Das Deutsche Recht (ius Teutonicum) und die Anfänge der städtischen Autonomie, [in:] Autonomie, Wirtschaft und Kultur der Hansestädte..., S. 94-100.

${ }^{14}$ P.H.J. van der Laan, Die städtische Autonomie in den nördlichen Niederlanden bis zum 17. Jahrhundert, [in:] Autonomie, Wirtschaft und Kultur der Hansestädte..., S. 101-110.

15 S. Selzer, Die mittelalterliche Hanse, Darmstadt 2010, S. 10. Hieraus auch das folgende Zitat. 
zur sozialistischen Geschichtsdeutung auf seinerzeit übliche Termini wie „Feudalgesellschaft“ usw. oder auf wirklich nur am Rande vorkommende Verweise auf Thesen und Ansichten kommunistischer Theoretiker. Summa summarum sind die betreffenden Beiträge somit heute immer noch von großem Wert.

Über die Gründe, warum sich die Hanseforschung des Themas seither kaum mehr angenommen hat, kann man lediglich spekulieren: Andere Themen rückten warum auch immer in den Vordergrund und zogen das Hauptaugenmerk der zahlenmäßig ohnehin überschaubaren Forscher offenkundig eher auf $\operatorname{sich}^{16}$. Die Autonomie der Hansestädte in ihrer Genese und vollen Ausprägung stellt indes in jedem Fall ein nach wie vor spannendes Untersuchungsgebiet dar, insbesondere für die lange sowieso kaum berücksichtigten vielen kleineren und kleinen Hansestädte, deren Erforschung für das von mir vehement propagierte Forschungsfeld einer Hansegeschichte als Regionalgeschichte vielversprechend erscheint ${ }^{17}$.

Für unsere Zwecke hilfreich ist die Definition, die seinerzeit, 1980/84, von städtischer Autonomie als historischem Phänomen gegeben wurde, umso mehr als die mittelalterliche Rechtssprache keinen direkten Begriff dafür parat hält und ihn - etwa in der geläufigen Formel iura et libertates et consuetudines lediglich umschreibt ${ }^{18}$. Auch die Literatur wartet mit einer großen, uneinheitlichen Spannbreite von Begriffen wie Unabhängigkeit, Souveränität, Städtefreiheit usw. auf. So versteht z.B. Evamaria Engel unter städtischer Autonomie ganz allgemein ein ganzes Bündel städtischer „Sonderrechte“, wozu 1) das Recht zur durch einen Stadtrat wahrgenommenen Selbstverwaltung, 2) die Ausübung der niederen und auch höheren Gerichtsbarkeit, 3) die Befähigung zur Rechtssetzung bis hin zur Abfassung ganzer Rechtsbücher, 4) die Möglichkeit zur Bündnis- und Einungspolitik und 5) überhaupt einer eigenen „Außenpolitik“, 6) das Vermögen zur politischen und ökonomischen Einflussnahme auf das über den unmittelbaren Geltungsbereich des Stadtrechts hinausgehende städtische Umland und zuletzt 7) das Recht zur Organisation als Land- oder Reichsstand unter Einschluss gewisser Widerstandsrechte gegen die zugeordnete

${ }^{16}$ Siehe den Forschungsüberblick bei O. Auge, Vom Städtebund zur kaufmännischen Interessensgemeinschaft. Der Beitrag der Hansehistoriker zur Stadtgeschichtsforschung der letzten 20 Jahre, [in:] Städte im Mittelalter und in der frühen Neuzeit als Forschungsthema in den letzten zwanzig Jahren. Abhandlungen und erweiterte Beiträge der 30. wissenschaftlichen Konferenz des Archivs der Hauptstadt Prag, hrsg. v. O. Fejtová, Prag 2015, S. 563-578.

${ }^{17}$ Idem, Hansegeschichte als Regionalgeschichte? Zur Diskussion um ein gar nicht so neues Forschungsdesign, [in:] Hanse und Stadt. Akteure, Strukturen und Entwicklungen im regionalen und europäischen Raum. Festschrift für Rolf Hammel-Kiesow zum 65. Geburtstag, hrsg. v. M. Hundt, J. Lokers, Lübeck 2014, S. 3-14; Hansegeschichte als Regionalgeschichte. Beiträge einer internationalen und interdisziplinären Winterschule in Greifswald vom 20. bis 24. Februar 2012, hrsg. v. O. Auge, Frankfurt a. M. u.a. 2014.

18 Dazu E. Müller-Mertens, op. cit., S. 13. Auch zum Folgenden. 
Landesherrschaft zählen ${ }^{19}$. In Anlehnung an die schon ältere Begriffsprägung Hans Strahms von der „Bestfreiheit“ ${ }^{\star 20}$ ergänzt Horst Wernicke diese Kriterien im Hinblick auf Autonomieerfordernisse für eine Hansemitgliedschaft in der Form, dass der städtische Rat eine eigene Satzungsgewalt, die sog. willkore, innehaben und die innere Verwaltung der Stadt ungehindert wahrnehmen, dass die betreffende Stadt als „künstliche Rechtsperson“ fungieren und über eine eigene Gebietsherrschaft verfügen sowie als eigener Rechts- und Steuerbezirk mit städtischer Münz- und Zollhoheit fungieren sollte ${ }^{21}$. Tatsächlich sind dies alles Aspekte, die uns im Folgenden im zu skizzierenden Spannungsfeld begegnen werden, in das sich die mittelalterlichen Hansestädte zwischen Autonomie und Landesherrschaft gestellt sahen.

II.

Es ist an sich klar, sollte aber doch nochmals ausdrücklich betont werden, dass der genaue Umfang der jeweiligen Autonomie von Hansestadt zu Hansestadt verschieden sein konnte und war und dass überhaupt nur die wenigsten Städte den Maximalumfang an Autonomie in Form eines quasi-souveränen Status erlangten. Einen solchen hatte zuvorderst Lübeck als Reichsstadt und faktisches Haupt der Hanse inne. Anschaulich beschrieb ein Vertreter seines Rates gegenüber der Römischen Kurie diesen Sachverhalt im Jahr 1366, als er erklärte, Lübeck sei eine niemand anderem als dem Reich und dem Kaiser untergebene Reichsstadt, die anstatt des Kaisers durch Ratsherren aus der Mitte ihrer Bürger regiert werde ${ }^{22}$. Diese hätten die höchste Gewalt über alle Bürger und Einwohner der Stadt. Lübeck sei zudem gerichtlicher Oberhof für mehr als 30 der bedeutendsten deutschen Städte, was sonst keine Stadt Deutschlands von sich behaupten könne. Gegen ihre Rechtssprüche könne man allein vor dem Hofgericht des Kaisers in Berufung gehen. Mit eigenen Mitteln und eigenen Söldnern bewahre Lübeck Frieden und Sicherheit auf den Straßen. Diese vollumfängliche Autonomie oder „Bestfreiheit" hatte die Stadt nun nicht auf einen Schlag erlangt, sondern in einem längeren Prozess seit ihrer Gründung um die Mitte des 12. Jahrhunderts bis zum berühmt gewordenen

\footnotetext{
19 E. Engel, op. cit., S. 48.
}

${ }^{20}$ H. Strahm, Stadtluft macht frei, [in:] Das Problem der Freiheit in der Deutschen und Schweizerischen Geschichte, hrsg. v. Konstanzer Arbeitskreis für mittelalterliche Geschichte, Konstanz 1954, S. 103-121, hier S. 18.

${ }^{21}$ H. Wernicke, op. cit., S. 38.

22 Dazu und zum Folgenden Urkundenbuch der Stadt Lübeck, Bd. 3: Urkunden bis 1350, Lübeck 1871, Nr. 595 (1366 Okt. 10), S. 633. „Lübeck sei Reichsstadt, die niemand anderem als dem Reich und dem Kaiser untergeben, und werde an Kaisers statt durch Ratsherren aus der Zahl ihrer Bürger regiert. Diese hätten die höchste Gewalt über alle Bürger und Einwohner“, nach E. Müller-Mertens, op. cit., S. 11f., der seinerseits nach der Übersetzung der Quellenstelle bei H. Reincke, Kaiser Karl IV. und die deutsche Hanse, Lübeck 1931, S. 33f. zitiert. 
Reichsfreiheitsbrief aus dem Jahr 1226 und darüber hinausgehend erreicht, wobei sie - gewiss vielfach mehr geschickt reagierend als bewusst planend - stark von den konkurrierenden Interessen der um Macht und Hegemonie in der südwestlichen Ostseeregion ringenden Herrscher profitierte: Der Sachsenherzog Heinrich der Löwe (*1129; †1195) setzte sich so aus ökonomischen Gründen gegen seinen Lehnsmann Graf Adolf II. von Holstein $(* 1128 ; \uparrow 1164)$ als neuer Stadtherr durch und förderte nun Lübeck 1159 in vielerlei Hinsicht ${ }^{23}$. Kaiser Friedrich I. Barbarossa $(* 1122 ; \uparrow 1190)$ wiederum stattete Lübeck nach der Verdrängung Herzog Heinrichs als Stadtherr 1181/88 mit umfänglichen neuen Privilegien, auch zu Lasten der benachbarten Grafschaften Holstein und Ratzeburg, aus ${ }^{24}$. Auf die kaiserliche Stadtherrschaft folgte, nach dem kurzen Interim, in dem der holsteinische Graf Adolf III. (*1160; $† 1225)$ faktisch als Stadtherr restituiert wurde ${ }^{25}$, die Zeit einer Meiner Oberhoheit des dänischen Königs. Genau in die Phase dieses Übergangs fällt 1201 nicht von ungefähr der Erstbeleg für städtische consules ${ }^{26}$. Innerhalb des alten römisch-deutschen Reiches sind solche Ratmänner nur noch für Utrecht mit der Erstnennung zum Jahr 1196 früher nachweisbar ${ }^{27}$. Die Zugehörigkeit zur pax Danica seit 1201 bedeutete für die Lübecker Kaufleute ungestörten und profitablen Handel im gesamten Ostseeraum. Lübeck entwickelte sich - zu Lasten der dänischen Kaufleute - zur „Boomtown“ im wahrsten Sinne des Wortes, wie unter anderem Matthias Hardt gezeigt hat ${ }^{28}$. Als jedoch der Stern des dänischen Königs

${ }^{23}$ R. Hammel-Kiesow, Die Anfänge Lübecks: Von der abotritischen Landnahme bis zur Eingliederung in die Grafschaft Holstein-Stormarn, [in:] Lübeckische Geschichte, hrsg. v. A. Graßmann, Lübeck 1988, S. 6-49, hier S. 49; G. Fehring, Lübeck zur Zeit der Welfen (1125-1235): Archäologische Erkenntnisse zu Topographie, Grundstücks- und Bebauungsstrukturen, [in:] Heinrich der Löwe und seine Zeit. Herrschaft und Repräsentation der Welfen 1125-1235. Katalog der Ausstellung Braunschweig 1995, hrsg. v. J. Lurckhardt, F. Niehoff, G. Biegel, Teilband 2, München 1995, S. 408-417; R. HammelKiesow, O. Pelc, Landesausbau, Territorialherrschaft, Produktion und Handel im Hohen und Späten Mittelalter, [in:] Geschichte Schleswig-Holsteins. Von den Anfängen bis zur Gegenwart, hrsg. v. U. Lange, Neumünster 2003², S. 59-134, hier S. 76; W. Lammers, Geschichte Schleswig-Holsteins, Bd. 4, 1: Das Hochmittelalter bis zur Schlacht von Bornhöved, Neumünster 1981, S. 315.

${ }^{24}$ E. Hoffmann, Lübeck im Hoch- und Spätmittelalter: Die große Zeit Lübecks, [in:] Lübeckische Geschichte, hrsg. v. A. Graßmann, Lübeck 1988, S. 79-340, hier S. 105-107.

${ }_{25}$ Ibidem, S. 107-109; M. Schürrer, Die Schauenburger in Nordelbien. Die Entwicklung gräflicher Handlungsspielräume im 12. Jahrhundert, Frankfurt a. M. 2017, S. $273-277$.

${ }^{26}$ E. Hoffmann, Lübeck im Hoch- und Spätmittelalter..., S. 110; D. Wille-Jørgensen, Das Ostseeimperium der Waldemaren: Dänische Expansion 1160-1227, [in:] Dänen in Lübeck = Danskere i Lübeck: 1203-2003, hrsg. v. M. Gläser, D. Mührenberg, P.B. Hansen, Lübeck 2003, S. 26-35; O. Pelc, Lübeck unter der Herrschaft Waldemars II. von Dänemark, [in:] Dänen in Lübeck = Danskere i Lübeck..., S. 45-50.

27 E. Hoffmann, Lübeck im Hoch- und Spätmittelalter ..., S. 110.

${ }^{28}$ M. Hardt, Lübeck in der Zeit Arnolds, [in:] Die Chronik Arnolds von Lübeck. Neue Wege zu ihrem Verständnis, hrsg. v. S. Freund, B. Schütte, Frankfurt a. M. 2008, S. 175-190, hier S. 183; vgl. E. Hoffmann, Die Bedeutung der Schlacht von Bornhöved für die deutsche und skandinavische Geschichte, ,Zeitschrift des Vereins für Lübeckische Geschichte und Altertumskunde“1977, Bd. 57, S. 9-37, hier S. 19. 
ab 1223 zum Sinkflug ansetzte und gleichzeitig der Argwohn der Bürger gegenüber seiner Politik und Stadtherrschaft immer größer geworden war, wechselte die Stadt aus eigenem freien Willen und auf eigene Kosten, wie urkundlich betont wurde ${ }^{29}$, die Seite und wandte sich an Kaiser Friedrich II. (*1194; $† 1250)$, der ihr darauf seinerseits aus eigenen politischen Interessen 1226 das Recht einräumte, von nun an eine „freie“, d.h. allein dem König unterstehende und zum Reichsgut zu rechnende Stadt zu sein, die niemals vom unmittelbaren Reichsbesitz getrennt werden dürfe ${ }^{30}$. Die Aufgabe des in Aussicht gestellten königlichen Schutzes sollte ein dafür eigens zu entlohnender fürstlicher rector aus der Nachbarschaft Lübecks wahrnehmen. Im Regelfall lag das Amt künftig in den Händen von Fürsten, die ,nicht stark genug war(en), um der städtischen Freiheit gefährlich zu werden, aber doch noch stark genug, um ihr nützliche Hilfe zu leisten“"31. Zusätzlich verlieh der Kaiser der Stadt damals umfängliche Privilegien, die nahezu sämtlich zu Lasten des holsteinischen Grafen gingen und durch die er Rechte vergabte, die er gar nicht besa $\beta^{32}$. Auch verfügte der Kaiser nicht über die Macht, die Bestimmungen seines Freiheitsbriefs durchzusetzen. Dieser war für Lübeck zunächst nur ,ein Wechsel auf die Zukunft“"33. Doch vermochte die Stadt im Verein mit wechselnden Bündnispartnern ${ }^{34}$ und unter Ausnutzung ihrer weiter anwachsenden ökonomischen und politischen Macht ihre 1226 verbriefte Selbstständigkeit erfolgreich zu behaupten - letztlich bis 1937.

III.

Diese „Erfolgsgeschichte“ städtischer Autonomie hatte Vorbildcharakter für andere Städte, wie das Beispiel des nicht weit von Lübeck entfernten Kiels zeigt ${ }^{35}$. Das 1242 vom holsteinischen Grafen Johann I. (*um 1229; †1263) mit dem lübi-

${ }^{29}$ Urkundenbuch der Stadt Lübeck, Bd. 1: 1139-1300, hrsg. v. dem Verein für Lübeckische Geschichte, Lübeck 1843, Nr. 29 (1223), S. 35f.; dazu E. Hoffmann, Lübeck im Hoch- und Spätmittelalter..., S. 117.

${ }^{30}$ O. Auge, Sieger und Verlierer oder: Das Ende der dänischen Hegemonie, das staufische Kaisertum und die Entstehung der Landesherrschaft in Norddeutschland im 13. Jahrhundert, [in:] Die Staufer und der Norden Deutschlands, hrsg. v. K.-H. Rueß, Göppingen 2016, S. 111-130, hier S. 120; E. Hoffmann, Lübeck im Hoch- und Spätmittelalter ..., S. 116-123.

${ }^{31}$ E. Hoffmann, Lübeck im Hoch- und Spätmittelalter..., S. 120, hier speziell zu Albrecht I. von Sachsen.

${ }^{32}$ H.-O. Gaethke, Knud VI. und Waldemar II. von Dänemark und Nordalbingien 1182-1227, Tl. 3, „Zeitschrift der Gesellschaft für Schleswig-Holsteinische Geschichte“ 1996, Bd. 121, S. 7-44, hier S. 33; R. Usinger, Deutsch-dänische Geschichte 1189-1227, Berlin 1863, S. 361.

${ }^{33}$ E. Hoffmann, Lübeck im Hoch- und Spätmittelalter..., S. 121.

${ }^{34}$ Siehe für die unmittelbare Folgezeit O. Auge, Die Grafen von Holstein, die Könige von Dänemark und die Reichsstadt Lübeck in der zweiten Hälfte des 13. Jahrhunderts: Konflikte und Bündnisse, im Druck, mit der dort genannten weiterführenden Literatur.

${ }^{35}$ Siehe zum Folgenden neben der speziell zitierten Literatur den Gesamtüberblick bei O. Auge, Kiel in der Geschichte. Facetten einer Stadtbiografie, Kiel-Hamburg 2016, S. 53-76. 
schem Recht ausgestattete Kiel strebte phasenweise im Schlepptau der Hanse dem Beispiel Lübecks spürbar nach, ohne jemals den Status einer vollautonomen Stadt zu erlangen. Vielmehr hatte Kiel im Mittelalter lange Zeit auch den Charakter einer gräflichen Residenz und immer mehr den eines Zentrums des holsteinischen Adels $^{36}$. Diese scheinbar widersprüchliche Verbindung - scheinbar, weil die meisten Hansestädte niemals volle Autonomie und Souveränität erlangten, sondern immer auch landes- bzw. stadtherrliche Städte blieben ${ }^{37}$ - bringt das mittelalterliche Stadtsiegel bestens zum Ausdruck ${ }^{38}$ : Umrahmt von der Umschrift + SIGILLUM : CIVIUM : KILENSIUM, was "Siegel der Kieler Bürger" bedeutet, ist darauf ein Schiff in vollen Segeln auf hoher See zu sehen. Es handelt sich offenbar nicht um die Darstellung einer klassischen Kogge, sondern eines älteren Schiffstypus. Am Heck des Schiffes sitzt in zeittypischer Kleidung ein Steuermann mit zum Schwur erhobener Hand als Fingerzeig auf die eidlich zusammengefügte Fahrgemeinschaft der Kaufleute zur See. Am Bug des Schiffes ist das Nesselblatt als Wappen der Grafen von Holstein zu sehen, die, wie gesagt, die Stadtherren waren.

1283 erhielt Kiel gemeinsam mit Hamburg vom dänischen König Erich V. Klipping (*um 1249; †1286) je eine Vitte, also einen Heringslandeplatz, in Falsterbo verliehen ${ }^{39}$. Die Heringsmessen in Schonen nahmen innerhalb des Ostseehandels eine herausragende Position ein und trugen wesentlich zum handelspolitischen Aufstieg Lübecks und der anderen wendischen Hansestädte bei $^{40}$. Kiel erhielt die Verbindung zu den Messen lange aufrecht, wie man weiß: Noch zum Ausgang des 15. Jahrhunderts lässt sich die Anlandung von Hering aus Schonen im Kieler Hafen nachweisen, eine Kieler Schonenfahrergilde begegnet erstmalig $1458^{41}$. Freilich hatte sich Lübeck bis 1352 schon große Teile der Kieler Vitte in Schonen angeeignet ${ }^{42} .1283$ war Kiel dann Vertragspartner der Städte

${ }^{36}$ Vgl. dazu auch H.G. Walther, Von der Holstenstadt der Schauenburger zur Landesstadt des holsteinischen Adels, 1242 bis 1544, [in:] Geschichte der Stadt Kiel, hrsg. v. J. Jensen, P. Wulf, Neumünster 1991, S. 13-58, hier S. 37-50.

37 R. Hammel-Kiesow, Die Hanse, München 20145, S. 107.

${ }_{38}$ Eine sehr gute Abbildung davon liefert H.G. Walther, op. cit., S. 39.

39 Schleswig-Holstein-Lauenburgische Regesten und Urkunden, Bd. 2: 1250-1300, hrsg. v. P. Hesse, Hamburg 1888, Nr. 641 (1283 Juli 20), S. 255, Bestätigung: Nr. 847 (1294 Okt. 4), S. 351; Hamburgisches Urkundenbuch, Bd. 1: 786-1300, hrsg. v. J. Lappenberg, Hamburg 1842, Nr. 806 (1283 Juli 20), S. 659; T. Hill, Kleine Städte in der Hanse. Das Beispiel Kiels (1250-1400), [in:] Ene vruntlike tohopesate. Beiträge zur Geschichte Pommerns, des Ostseeraumes und der Hanse. Festschrift für Horst Wernicke zum 65. Geburtstag, hrsg. v. S. Birli u.a., Hamburg 2016, S. 247-264, hier S. 254; H.G. Walther, op. cit., S. 38.

${ }^{40}$ C. Jahnke, Silber des Meeres. Fang und Vertrieb von Ostseehering zwischen Norwegen und Italien (12.-16. Jahrhundert), Köln u.a. 2000, S. 244-249.

${ }^{41}$ T. Hill, op. cit., S. 255, nach H. Landgraf, Bevölkerung und Wirtschaft Kiels im 15. Jahrhundert, Neumünster 1959, S. 104, 127; H.G. Walther, op. cit., S. 50.

${ }^{42}$ T. Hill, op. cit., S. 255; H.G. Walther, op. cit., S. 50 mit Hanserecesse. Die Recesse und andere Akten der Hansetage von 1256-1430, Abt. 1, Bd. 1, hrsg. v. der historischen Commission bei 
Lübeck, Hamburg, Wismar, Rostock, Stralsund, Greifswald, Demmin, Anklam und Stettin in einem Landfriedensbündnis zur Sicherung der Verkehrswege zu Wasser und zu Lande ${ }^{43}$. Helmut G. Walther möchte es deswegen von da an „mit gutem Grund" als Hansestadt bezeichnen, was er dadurch untermauert, dass der Kieler Rat im Jahr 1295 einen Beschluss mittrug, der Lübeck zur übergeordneten Rechtsinstanz für das hansische Handelskontor in Novgorod machen sollte ${ }^{44}$. Offenbar hatten damals Kieler Kaufleute Handelsinteressen, die sogar bis nach Russland hineinreichten. Doch hat Thomas Hill jüngst einer Einstufung Kiels als Hansestadt für das späte 13. Jahrhundert widersprochen. Erst ab 1356, als sich mit der Etablierung des Hansetages als politischem Forum der Hanse auch eine Städtehanse herauskristallisierte, könne man von einer Hansestadt Kiel sprechen ${ }^{45}$. Mit den innerdynastischen Turbulenzen, die 1315/21 zum Ende der Kieler Linie des holsteinischen Grafenhauses führten ${ }^{46}$, arrangierte sich Kiel nun in bester Weise, indem es von den gräflichen Profiteuren des Umsturzes, Gerhard III. (*um 1293; †134[0]) und Johann III. (*1297; †1359), die Zusicherung erhielt, den Stadtvogt künftig nur aus den Reihen der eigenen Bürger und im Einverständnis mit dem Rat zu wählen ${ }^{47}$. Auch sollte das stadtherrliche Befestigungsrecht fortan allein auf das Areal der Burg beschränkt sein ${ }^{48}$. Der nunmehr abgesetzte Johann II. (*1253; †1321) schenkte sodann 1317 das Dorf Wik dem Kieler Heilig-Geist-Spital und trat auch sein gräfliches Münzrecht an die Stadt $\mathrm{ab}^{49}$. Kiel nutzte also geschickt jedwede Gelegenheit, um die stadtherrlichen Rechte zu beschränken oder sie sich selbst anzueignen. Von Johann III. und seinem Nachfolger Adolf VII. (*um 1327; †1390) ließ sich die Stadt zudem die Zusage geben, die Stadtburg

der königl. Akademie der Wissenschaften, Leipzig 1870, Nr. $176 \S 12$ (1352), S. 108 und Nr. 178 (1352), S. 109. - Vgl. auch C. Jahnke, op. cit., S. 128, 402.

${ }^{43}$ Schleswig-Holstein-Lauenburgische Regesten und Urkunden, Bd. 2: 1250-1300, Nr. 640 (1283 Jun. 13), S. 254; W.-D. Mohrmann, Der Landfriede im Ostseeraum während des späten Mittelalters, Kallmünz 1972, S. 50-61.

${ }^{44}$ H.G. Walther, op. cit., S. 38. Walther folgt dabei C. Jessen, Kiel als Mitglied der deutschen Hanse, „Zeitschrift der Gesellschaft für Schleswig-Holsteinische Geschichte“ 1882, Bd. 12, S. 131161; H. Willert, Anfänge und frühe Entwicklung der Städte Kiel, Oldesloe und Plön, Neumünster 1990, S. 119, 170. Zu 1295 vgl. Urkundenbuch der Stadt Lübeck, Bd. 1: 1139-1300, hrsg. v. dem Verein für Lübeckische Geschichte, Lübeck 1843, Nr. 642 (1295), S. 578.

45 T. Hill, op. cit., S. 264.

46 Vgl. dazu E. Hoffmann, Spätmittelalter und Reformationszeit, Geschichte Schleswig-Holsteins Bd. 4/2, 1.-4. Lief., Neumünster 1990, S. 66-76.

47 Schleswig-Holstein-Lauenburgische Regesten und Urkunden, Bd. 3: 1301-1340, hrsg. v. P. Hasse, Hamburg-Leipzig 1891, Nr. 323 (1315 Nov. 1), S. 170f.; Nr. 351 (1317 Aug. 1), S. 188. Dazu und zum Folgenden H.G. Walther, op. cit., S. 39f.

${ }_{48}$ Schleswig-Holstein-Lauenburgische Regesten und Urkunden, Bd. 3: 1301-1340, Nr. 323 (1315 Nov. 1), S. $170 \mathrm{f}$.

49 Schleswig-Holstein-Lauenburgische Regesten und Urkunden, Bd. 3: 1301-1340, Nr. 354 (1317 Okt. 31), S. 189; Nr. 374 (1318 Nov. 10), S. 202. 
künftig nicht mehr ohne Zustimmung des Rats zu verpfänden. Zuvor hatte sie dieselbe auf ihre Kosten ausgelöst, nachdem der dauernd unter akuter Geldnot leidende Graf sie an den Ritter Nikolaus Split verpfändet hatte ${ }^{50}$. Auch ihre Rechte an St. Nikolai traten die gräflichen Stadtherren im 14. Jahrhundert ab, aber nicht an die Städter, sondern an die Augustinerchorherren, die seit 1332 ihren Sitz im nahen Bordesholm hatten ${ }^{51}$. Deren Versuche, ihr Stift aus Bordesholm nach Kiel zu verlegen, scheiterten indes am harten Widerstand der Kieler Bürger. Diese wünschten nämlich keinen derartigen kirchlichen Machtfaktor in ihren Stadtmauern. Auf dem Höhepunkt seiner städtischen Autonomie beteiligte sich Kiel am Krieg der Hansestädte, den diese ab 1361 gegen den dänischen König wegen der Eroberung Gotlands mit der Hauptstadt Visby führten ${ }^{52}$. Dazu stellte die Stadt ein Schiff von 40 Lasten mit 40 Bewaffneten für die hansische Kriegsflotte und einen Beitrag von 42 Mark Pfundzoll für die Kriegskasse bereit. Vor Helsingborg ging freilich das Schiff mit Besatzung und Ausrüstung verloren, was nun die Kieler veranlasste, von den anderen Städten eine Entschädigung für den schweren Verlust zu verlangen. Trotz wiederholten Drängens erhielt die Stadt aber wohl keinen vollständigen Ersatz. Kiel verhandelte dann zwar im hansischen Auftrag gemeinsam mit Hamburg mit den Grafen von Holstein, war bei den Friedensverhandlungen mit dem dänischen König zugegen und beteiligte sich am Friedensschluss mit demselben am 30. September $1365^{53}$. Doch brachte es sich nach der Wiederaufnahme der Kampfhandlungen im Kontext der Kölner Konföderation von 1367 nicht mehr aktiv ins Kriegsgeschehen ein. Die Enttäuschung über die mangelnde Entschädigung für die verlorene Kogge mag ein Grund dafür gewesen sein, die geringer werdenden eigenen Handelsinteressen bei den Schonenmessen, um die es bei dem Krieg eigentlich ging, ein anderer. Nicht zuletzt aber war Kiels Stadtherr Adolf VII. im Sommer 1367 zum Lager des dänischen Königs übergewechselt, weswegen man in Kiel genau abwägen musste, ob man sich künftig für die Interessen der anderen Städte im Ostseehandel oder für die eigenen im holsteinischen Nahbereich stark machen wollte. Tatsächlich hatte sich Kiel mittlerweile zu einem bedeutenden regionalen Zentralort im holsteinischen Herrschaftsgefüge entwickelt. Die eigenen Vorteile und das Bemühen um ein gutes Verhältnis zum Stadtherrn gaben letztlich den Ausschlag. Die 1370

${ }^{50}$ Schleswig-Holsteinische Regesten und Urkunden, Bd. 4: 1341-1375, hrsg. v. V. Pauls, Neumünster 1924, Nr. 517 (1351 Dez. 27), S. 345; Nr. 522 (1352 Jan. 20), S. 346. H.G. Walther, op. cit., S. $51 \mathrm{f}$.

${ }^{51}$ H.G. Walther, op. cit., S. 50f. Auch zum Folgenden. Zum Augustinerchorherrenstift Bordesholm siehe E. Bünz, Die Aufhebung der holsteinischen Augustiner-Chorherrenstifte Bordesholm und Segeberg in der Reformationszeit, [in:] Reform - Sequestration - Säkularisation: Die Niederlassungen der Augustiner-Chorherren im Zeitalter der Reformation und am Ende des alten Reiches, hrsg. v. W. Müller, Paring 2005, S. 39-78.

${ }_{52}$ Dazu und zum Folgenden H.G. Walther, op. cit., S. 42f. mit C. Jessen, op. cit., S. 143-150.

${ }^{53}$ Hanserecesse, Abt. 1, Bd. 1, Nr. 369 (1365 Sep. 30), S. 318. 
genau nach dem Abschluss des für die Hansestädte günstigen Stralsunder Friedens erfolgende Verhansung Kiels mochte die Stadt in ihrer Haltung bestärken: Kiel wurde wegen der Prägung schlechter Münzen von der Nutzung der hansischen Privilegien ausgeschlossen ${ }^{54}$. Obwohl Kiel dann bereits im Folgejahr wieder in die Hanse aufgenommen wurde, blieb sein Verhältnis zu ihr fortan problematisch. Dies zeigte sich etwa bei einem Vorfall des Jahres 1386, als ein Lübecker Söldnerkontingent bei der Verfolgung holsteinischer Adeliger in einen Hinterhalt geriet und vor den Augen der Kieler niedergemacht wurde, weil diese ihr Stadttor nicht öffnen wollten ${ }^{55}$. Lübeck beantragte daraufhin erneut die Verhansung Kiels. Das schwierige Verhältnis kam auch im nur noch mäßigen Engagement der Stadt für hansische Aktivitäten zum Ausdruck: Zwar war Kiel auf den Hansetagen in der ersten Hälfte des 15. Jahrhunderts regelmäßig vertreten. Aber es leistete mit lediglich drei Bewaffneten zwischen 1407 und 1475 jeweils den geringsten Beitrag zu den hansischen Bündnissen ${ }^{56}$. Gleichzeitig entwickelte sich die Stadt zu einer Art Piratennest, was den anderen Hansestädten verständlicherweise ein Dorn im Auge war ${ }^{57}$. Auf dem Wismarer Tag von 1417 forderte Lübeck folgerichtig die Rückgabe von Beutegut, das die Piraten in Kiel umgeschlagen hatten. Das hinderte die Kaperfahrer nicht, weiterhin den Kieler Hafen anzusteuern. Dies erklärt auch, warum Lübeck ein starkes Interesse hatte, sich die Stadt 1472 als Pfand von Christian I. (*1426; †1481) zu sichern ${ }^{58}$ : Man wollte das Piratennest Kiel endlich besser kontrollieren. Zur wachsenden Entfremdung von der Hanse passte es, dass die Städte Holsteins 1496 durch Friedrich I. $(* 1471 ; \uparrow 1533)$ vom Rechtszug nach Lübeck befreit wurden, den die einzelnen Stadtrechtsurkunden schriftlich fixiert hatten, und dass stattdessen ein holsteinisches Vierstädtegericht, bestehend aus den Vertretern Kiels, Itzehoes, Rendsburgs und Oldesloes, als neuer gerichtlicher Oberhof ins Leben gerufen wurde ${ }^{59}$. Letztlich war dann das offizielle

${ }^{54}$ G. Hatz, Die Anfänge des Münzwesens in Holstein. Die Prägungen der Grafen von Schauenburg bis 1325, [in:] Numismatische Studien Heft 5, hrsg. v. W. Hävernick, Hamburg 1952, S. 114-116.

${ }^{55}$ E. Hoffmann, Spätmittelalter ..., S. $216 f$.

${ }^{56}$ H.G. Walther, op. cit., S. 44; C. Jessen, op. cit., S. 154.

${ }^{57}$ Dazu und zum Folgenden H.G. Walther, op. cit., S. 44 mit C. Jessen, op. cit., S. 155; Die Lübecker Briefe des Kieler Stadtarchivs 1422-1534, hrsg. v. A. Wetzel, Kiel 1883, Mitteilungen der Gesellschaft für Kieler Stadtgeschichte 5, S. 1-9, Nr. 1-4.

${ }^{58}$ H.G. Walther, op. cit., S. 48; C. Jessen, op. cit., S. 147f.; C. Wehrmann, Die Verpfändung Kiels an Lübeck im Jahre 1469, „Zeitschrift des Vereins für lübeckische Geschichte und Altertumskunde“ 1863, Heft 2, S. 38-74; Die Lübecker Briefe des Kieler Stadtarchivs..., S. 74-78, Anhang Nr. 1-2.

${ }^{59}$ O. Auge, Zur Rolle von Klerus und Städten auf den schleswig-holsteinischen Landtagen bis zur Mitte des 16. Jahrhunderts, [in:] Der Vertrag von Ripen 1460 und die Anfänge der politischen Partizipation in Schleswig-Holstein, im Reich und in Nordeuropa. Ergebnisse einer internationalen Tagung der Abteilung für Regionalgeschichte der CAU zu Kiel vom 5. bis 7. März 2010, hrsg. v. O. Auge, B. Büsing, Ostfildern 2012, S. 155-177, hier S. 175; H.G. Walther, op. cit., S. 50; Das älteste Urteilsbuch des Holsteinischen Vierstädtegerichts 1497-1574, hrsg. v. F. Grundlach, Kiel 1925. 
Ende von Kiels Hansemitgliedschaft wegen „Verwirkung und Ungehorsam“ im Zeitraum vor 1518 nur der konsequente Schlusspunkt einer langen Entwicklung ${ }^{60}$. Ein Anlauf zur Wiederaufnahme im Jahr 1554 wurde von Lübeck abgeblockt ${ }^{61}$.

IV.

Das eben näher vorgestellte Beispiel Kiels bringt das zum Eingang des Vortrags benannte Spannungsfeld zwischen Autonomie und Landes- oder Stadtherrschaft anschaulich nahe. Es zeigt auch, was Horst Wernicke damit meint, wenn er davon spricht, dass die einzelstädtische Autonomie im Rahmen der Hanse wiederum beschränkt wurde ${ }^{62}$. Die einzelne Stadt hatte sich hanseweiten oder zumindest von einer Mehrheit der Hansestädte vertretenen Rechten und Zielen unterzuordnen, wollte sie nicht Gefahr laufen, wieder aus der Hanse ausgeschlossen zu werden. Von Vorteil konnte es dabei sein, dass eine hanseweite Willensbildung oftmals gar nicht realisiert werden konnte ${ }^{63}$.

Die Forschung ist der Ansicht, dass sich der ursprüngliche Konsens zwischen den Hansestädten und ihren geistlichen oder weltlichen Stadtherren, denen sie im 12. und 13 Jahrhundert eine umfängliche Förderung - wie vorhin am Lübecker Beispiel gezeigt - verdankten, zu einer tiefen Kluft entwickelte, die vielfach in bewaffneten Konflikten endete ${ }^{64}$. Die Fürsten wollten es im 14. und vollends im 15. Jahrhundert nicht länger dulden, dass die Städte ein ums andere Recht von ihnen erwarben und im gleichen Atemzug eine immer selbstständigere Position ihnen gegenüber bis hin zur politisch unabhängigen „Außenpolitik“ betrieben und sich mehr und mehr aus dem jeweiligen Territorialverband zu lösen suchten. Das Ziel weitgehender Autonomie, der „Bestfreiheit“, kollidierte mit dem Bemühen der in mancherlei Hinsicht bereits vorabsolutistischen Fürsten um eine verstärkte Intensivierung ihrer Landesherrschaft. Die Übereinkunft des dänischen Königs Christian I. mit dem brandenburgischen Markgrafen Albrecht Achilles (*1414; $\dagger 1486$ ) aus dem Jahr 1474, wonach den Städten in ihren Landen das Recht zur Selbstregierung genommen und deren Macht gebrochen, auch ihnen wieder die Verfügungsgewalt über Zoll, Steuern und Recht abgerungen werden sollte, vereint diese fürstlichen Bestrebungen wie unter einem Brennglas gebündelt ${ }^{65}$. Auf die für

${ }^{60}$ E. Pomsel, Das Ende der Hansemitgliedschaft Kiels, „Mitteilungen der Gesellschaft für Kieler Stadtgeschichte“ 1949, Bd. 45, S. 11f.

${ }^{61}$ Die Lübecker Briefe des Kieler Stadtarchivs..., S. 76f., Anhang Nr. 3.

${ }^{62}$ H.G. Wernicke, op. cit., S. 44.

${ }^{63}$ R. Hammel-Kiesow, Die Hanse, S. 71-81.

${ }^{64}$ Dazu und zum Folgenden M. Puhle, Politik und Diplomatie, [in:] Die Hanse, hrsg. v. R. Hammel-Kiesow, M. Puhle, S. Wittenburg, Darmstadt 2009, S. 160-173, hier S. 165.

${ }^{65}$ E. Engel, op. cit., S. 47 mit F. Priebatsch, Die Hohenzollern und die Städte in der Mark im 15. Jahrhundert, Berlin 1892, S. 15. 
viele Hansestädte allmählich immer bedrohlichere Situation reagierte der Hansetag von 1418 mit dem Versuch eines umfassenden Bündnisses, Tohopesate genannt ${ }^{66}$. Es sollte für die Dauer von zwölf Jahren vereinbart werden und beinhaltete vor allem die Verpflichtung zur gegenseitigen Warnung vor Gefahren und zur Hilfe bei jedwedem Angriff auf eine verbündete Stadt. Zunächst sollten dabei die nächstliegenden vier Städte zu Hilfe eilen, und falls diese nicht der betreffenden Lage Herr werden würden, sollten weitere vier Städte hinzugezogen werden. Sollte sich dann herausstellen, dass die acht Städte zu schwach zur wirksamen Hilfe seien, sollte der ganze Bund intervenieren. Zu diesem Zweck wurde die Stärke des Truppenkontingents, das ein jedes Bündnismitglied beizusteuern hatte, festgelegt. Dieser Entwurf zu einer Tohopesate wurde auf dem Hansetag als Geheimangelegenheit behandelt, um so anscheinend nicht gegen das kaiserliche Verbot von Städtebündnissen aus dem Jahr 1356 zu verstoßen ${ }^{67}$. Auch ist er nie realisiert worden, was sich wiederum mit den allgemeinen Problemen im Hinblick auf eine konsensuale Willensbildung auf den Hansetagen erklären lässt. Offenbar führte gerade die absehbare Notwendigkeit zur Unterordnung der Autonomien der einzelnen Städte unter dem Dach des Bündnisses in den betreffenden Ratsgremien zur Ablehnung des Plans.

Die Auseinandersetzung zwischen der Hansestadt Halberstadt und ihrem Bischof in den Jahren 1423 bis $1425^{68}$ und der Konflikt zwischen Magdeburg und seinem Erzbischof zwischen 1430 und $1435^{69}$ zeigten aber nur zu deutlich, dass auf Seiten der Hansestädte dringender Handlungsbedarf bestand. Als dann noch die Stadt Cölln bei Berlin 1442 fast handstreichartig von Friedrich II. von Brandenburg $(* 1413 ; \uparrow 1471)$ eingenommen worden war $^{70}$ und im Jahr darauf der Fürstentag zu Wilsnack stattgefunden hatte, um gemeinsame Aktionen der Fürsten gegen ihre Städte zu vereinbaren $^{71}$, waren die Städte dann doch, unter Hintanstellung ihrer eigenen Vorbehalte, zu einem Städtebündnis bereit, was tatsächlich am 30. August 1443 in Lübeck zum

${ }^{66}$ Dazu und zum Folgenden M. Puhle, op. cit., S. 165; Hansisches Urkundenbuch, Bd. 6: 1415-1433, hrsg. v. dem Verein für hansische Geschichte, Leipzig 1905, Nr. 170 (1418 Jun. 24), S. 87-90. Vgl. zu den Tohopesaten auch R. Hammel-Kiesow, Die Hanse, S. 81f.; W. Bode, Hansische Bundesbestrebungen in der ersten Hälfte des 15. Jahrhunderts, „Hansische Geschichtsblätter“ 1920-1921, Bd. 46, S. 174-193; idem, Hansische Bundesbestrebungen in der ersten Hälfte des 15. Jahrhunderts, „Hansische Geschichtsblätter“ 1926, Bd. 51, S. $28-71$.

${ }^{67}$ M. Puhle, op. cit., S. 168. Auch zum Folgenden.

${ }_{68}$ M. Vollmath-Lindenthal, Die Stellung der Bischöfe in Halberstadt im Gefüge der politischen Landschaft (1300-1500), [in:] Geschichte und Kultur des Bistums Halberstadt. 804-1648, hrsg. v. A. Siebrecht, Halberstadt 2006, S. 555-562, hier S. 557.

${ }^{69}$ M. Springer, Städte im Krieg: Der Kampf Magdeburgs und seiner Verbündeten gegen den Erzbischof Günther in den Jahren 1431 bis 1435, [in:] Hanse, Städte, Bünde. Die sächsischen Städte zwischen Elbe und Weser um 1500, Bd. 1: Aufsätze, hrsg. v. M. Puhle, Magdeburg 1996, S. 191-199.

70 P.-M. Hahn, Geschichte Brandenburgs, München 2009, S. 36.

${ }^{71}$ E. Daenell, Die Blütezeit der Deutschen Hanse, Hansische Geschichte von der zweiten Hälfte des XIV. bis zum letzten Viertel des XV. Jahrhunderts, Bd. 2, Berlin 1906, S. 482f. 
Abschluss der ersten hansischen Tohopesate führte ${ }^{72}$. Für die Dauer von drei Jahren verbündeten sich 38 Städte, ,die Straßen zu schützen, dem Raub zu wehren, im Falle von Angriffen seitens der Fürsten und Herrn einander mit bewaffneter Macht beizusteuern, Erhebungen gegen die Räte nötigenfalls mit Gewalt zu dämpfen und ihren Bund gemeinsam gegen jeden zu verteidigen ${ }^{6 / 73}$. Zu diesem Zweck wurden die beteiligten wendischen, sächsischen, märkischen und pommerschen Städte in drei Drittel mit den Hauptorten Lübeck, Hamburg und Magdeburg eingeteilt. Von einer allgemeinen hansischen Tohopesate war das Bündnis freilich noch weit entfernt. Ohne zwar eine große Militäraktion in Gang bringen zu müssen, hatte es angesichts der nahezu zeitgleich ausgelösten Auseinandersetzungen pommerscher, mecklenburgischer und sächsischer Fürsten mit ihren Städten, insbesondere im Fall des 1444 mit einer Fehde vom Pommernherzog Bogislaw IX. (*1407; †1446) überzogenen Kolberg ${ }^{74}$, gleichwohl Bestand. Dieser erste Erfolg führte auf dem Hansetag vom 18. Mai 1447 dazu, dass das Bündnis neuaufgelegt und erweitert wurde ${ }^{75}$. Damit erlangte es jetzt in der Tat einen gesamthansischen Charakter. Denn auch die westfälischen und süderseeischen Städte schlossen sich an und wurden darin zu einem eigenen vierten Viertel zusammengefasst. Inhaltlich entsprach diese Tohopesate im Wesentlichen dem Bündnis von 1443 und galt für zehn Jahre. Ohne die märkischen Städte wurde es dann angesichts des Engagements norddeutscher Fürsten im Süddeutschen Städtekrieg von 1449/50 bereits am 9. April 1451 erneuert $^{76}$.

Auf lange Sicht konnten freilich auch diese Tohopesaten nicht verhindern, dass der Druck der fürstlichen Territorialherren auf den autonomen Status der Städte immer größer wurde, zumal sich die Städte nach 1451 nicht mehr zu einer regional übergreifenden gemeinsamen Bündnispolitik herbeifanden. Gegen Ende des 15. Jahrhunderts waren so etwa alle östlichen Städte des sächsischen Quartiers außer Magdeburg unterworfen und damit faktisch als Mitglieder der Hanse ausgeschieden ${ }^{77}$. Insgesamt schrumpfte die Zahl der Mitglieder immer weiter, was im 16. Jahrhundert dann verschiedene Maßnahmen der Reform und Reorganisation seitens der Hanse hervorrief, auf die hier im Einzelnen nicht mehr eingegangen werden $\mathrm{kann}^{78}$. Dazu gehörte allerdings im Jahr 1518 auch die Erstellung einer

72 M. Puhle, op. cit., S. 170.

${ }^{73}$ Zitat aus ibidem nach Hanserecesse 1431-1476, Abt. 2, Bd. 3, hrsg. v. dem Verein für hansische Geschichte, Leipzig 1881, Nr. 68 (1443 Aug. 30), S. 34. Auch zum Folgenden.

${ }_{74}$ M. Wehrmann, Geschichte von Pommern. Erster Band bis zur Reformation (1525), Gotha 1904, S. 199.

75 M. Puhle, op. cit., S. 170; Hanserecesse 1431-1476, Abt. 2, Bd. 3, Nr. $288 \S 23$ (1447 Mai 18), S. 181.

${ }^{76}$ M. Puhle, op. cit., S. 170f.

77 Ibidem, S. 171.

78 J. Sarnowsky, Das Ende der mittelalterlichen Hanse, [in:] Ene vruntlike tohopesate. Beiträge zu Geschichte Pommerns, des Ostseeraums und der Hanse: Festschrift für Horst Wernicke zum 65. Geburtstag, hrsg. v. S. Birli u.a., Hamburg 2016, S. 499-517. 
Liste, welche einstigen Hansestädte inzwischen ,abgedankt und abgeschnitten“ waren $^{79}$. Hierzu zählten auch die im Vorangehenden genannten Städte Salzwedel und Kiel.

Stichwort Autonomie: Das gerade zur Krise der Hanse im 15. Jahrhundert und zur nachhaltigen Integration eines großen Teils ihrer Mitgliedsstädte in landesherrliche Territorien Gesagte bedeutet nun nicht, dass damit zugleich das Ende ihrer Autonomie eingeläutet war. Wenn man unter Autonomie nämlich nicht allein den Zustand der „Bestfreiheit“ und Quasi-Souveränität versteht, über den auf lange Sicht nur Lübeck, Hamburg und Bremen verfügten, sondern jenes eingangs angeführte viel weiter gefasste Kriterienbündel, dann „,kann die städtische Autonomie im 15. Jahrhundert nicht als von der Herrschergewalt beseitigt angesehen werden, denn die Bürgergemeinde als Selbstverwaltungskörperschaft, als rechts- und handlungsfähige juristische Person, der Rat als Organ der Bürgerschaft bzw. des Patriziats blieben im spätmittelalterlich-frühneuzeitlichen Ständestaat bestehen, die Standesqualität der Städtebürger wurde gewahrt. Ihre ständische Repräsentation kam überhaupt erst zur Entfaltung ${ }^{\text {“80 }}$. Das lässt sich wiederum sehr gut am Beispiel Kiels verdeutlichen. Kiel wurde nicht nur Mitglied des neuen Vierstädtegerichts, wie gesagt, sondern es war auch landtagsfähig und schickte daher wie Flensburg, Schleswig, Rendsburg und Itzehoe regelmäßig Vertreter zu den ab 1460 zusammentretenden schleswig-holsteinischen Landtagen ${ }^{81}$. Als Versammlungsort diente dabei auch das Kieler Rathaus. In der Obhut des Kieler Bürgermeisters befand sich zudem zumindest eine Zeitlang die versiegelte Privilegienlade der Lande und der schleswig-holsteinischen Ritterschaft - das landständische Gedächtnis sozusagen ${ }^{82}$. Erst mit der im Geist des Absolutismus verfügten Auflösung des Landtags durch Herzog Christian Albrecht $(* 1641 ; \uparrow 1695)$ im Jahr 1675 endete diese bedeutende Phase politischer Partizipation und Autonomie Kiels und der anderen Städte ${ }^{83}$.

${ }^{79}$ Vgl. Hanserecesse 1477-1530, Abt. 3, Bd. 7, hrsg. vom Verein für Hansische Geschichte, Leipzig 1905, Nr. 108, § 292, S. 135.

${ }^{80}$ Zitat aus E. Müller-Mertens, op. cit., S. 27f.

${ }^{81}$ O. Auge, Zur Rolle von Klerus..., S. 175.

82 Ibidem, S. 176 mit W. Leverkus, Berichte über die Schleswig-Holsteinischen Landtage von 1525, 1526, 1533, 1540, [in:] Archiv für Staats- und Kirchengeschichte der Herzogtümer Schleswig, Holstein, Lauenburg und der angrenzenden Länder und Städte, hrsg. v. A. Michelsen, Bd. 4, Altona 1840, S. 451-505, hier S. 491.

${ }_{83}$ O. Auge, Christian Albrecht. Herzog - Stifter-Mensch, Kiel-Hamburg 2016, S. $129 f$. 


\section{LITERATURVERZEICHNIS}

\section{Quellen}

Die Lübecker Briefe des Kieler Stadtarchivs 1422-1534, hrsg. v. A. Wetzel, Kiel 1883, S. 1-9, Nr. 1-4, S. 74-78, Anhang Nr. 1 und 2.

Das älteste Urteilsbuch des Holsteinischen Vierstädtegerichts 1497-1574, hrsg. v. F. Grundlach, Kiel 1925.

Hamburgisches Urkundenbuch, Bd. 1: 786-1300, hrsg. v. J. Lappenberg, Hamburg 1842, Nr. 806, S. 659 .

Hansisches Urkundenbuch, Bd. 6: 1415-1433, hrsg. v. dem Verein für hansische Geschichte, Leipzig 1905, Nr. 170, S. 87-90.

Schleswig-Holstein-Lauenburgische Regesten und Urkunden, Bd. 2: 1250-1300, hrsg. v. P. Hesse, Hamburg 1888, Nr. 640, S. 254; Nr. 641, S. 255, Bestätigung: Nr. 847, S. 351.

Schleswig-Holstein-Lauenburgische Regesten und Urkunden, Bd. 3: 1301-1340, hrsg. v. P. Hasse, Hamburg-Leipzig 1891, Nr. 323, S. 170f.; Nr. 351, S. 188, Nr. 354, S. 189; Nr. 374, S. 202.

Schleswig-Holsteinische Regesten und Urkunden, Bd. 4: 1341-1375, Hanserecesse. Die Recesse und andere Akten der Hansetage von 1256-1430, Abt. 1, Bd. 1, hrsg. v. der historischen Commission bei der königl. Akademie der Wissenschaften, Leipzig 1870, Nr. $176 \S 12$ (1352), S. 108; Nr. 178 (1352), S. 109.

Urkundenbuch der Stadt Lübeck, Bd. 1: 1139-1300, hrsg. v. dem Verein für Lübeckische Geschichte, Lübeck 1843, Nr. 29, S. 35f.; Nr. 642, S. 578.

Urkundenbuch der Stadt Lübeck, Bd. 3: Urkunden bis 1350, Lübeck 1871, Nr. 595, S. 633.

\section{Literatur}

Auge O., Christian Albrecht. Herzog - Stifter-Mensch, Kiel-Hamburg 2016.

Auge O., Die Grafen von Holstein, die Könige von Dänemark und die Reichsstadt Lübeck in der zweiten Hälfte des 13. Jahrhunderts: Konflikte und Bündnisse, im Druck.

Auge O., Hansegeschichte als Regionalgeschichte? Zur Diskussion um ein gar nicht so neues Forschungsdesign, [in:] Hanse und Stadt. Akteure, Strukturen und Entwicklungen im regionalen und europäischen Raum. Festschrift für Rolf Hammel-Kiesow zum 65. Geburtstag, hrsg. v. M. Hundt, J. Lokers, Lübeck 2014, S. 3-14.

Auge O., Kiel in der Geschichte. Facetten einer Stadtbiografie, Kiel-Hamburg 2016.

Auge O., Sieger und Verlierer oder: Das Ende der dänischen Hegemonie, das staufische Kaisertum und die Entstehung der Landesherrschaft in Norddeutschland im 13. Jahrhundert, [in:] Die Staufer und der Norden Deutschlands, hrsg. v. K.-H. Rueß, Göppingen 2016, S. 111-130.

Auge O., Vom Städtebund zur kaufmännischen Interessensgemeinschaft. Der Beitrag der Hansehistoriker zur Stadtgeschichtsforschung der letzten 20 Jahre, [in:] Städte im Mittelalter und in der frühen Neuzeit als Forschungsthema in den letzten zwanzig Jahren. Abhandlungen und erweiterte Beiträge der 30. wissenschaftlichen Konferenz des Archivs der Hauptstadt Prag, hrsg. v. O. Fejtová, Prag 2015, S. 563-578.

Auge O., Zur Rolle von Klerus und Städten auf den schleswig-holsteinischen Landtagen bis zur Mitte des 16. Jahrhunderts, [in:] Der Vertrag von Ripen 1460 und die Anfänge der politischen Partizipation in Schleswig-Holstein, im Reich und in Nordeuropa. Ergebnisse einer internationalen Tagung der Abteilung für Regionalgeschichte der CAU zu Kiel vom 5. bis 7. März 2010, hrsg. v. O. Auge, B. Büsing, Ostfildern 2012, S. 155-177.

Autonomie, Wirtschaft und Kultur der Hansestädte. Johannes Schildhauer zum 65. Geburtstag, hrsg. v. K. Fritze, E. Müller-Mertens, W. Stark, Weimar 1984. 
Bode W., Hansische Bundesbestrebungen in der ersten Hälfte des 15. Jahrhunderts, „Hansische Geschichtsblätter" 1920-1921, Bd. 46, S. 174-193.

Bode W., Hansische Bundesbestrebungen in der ersten Hälfte des 15. Jahrhunderts, „Hansische Geschichtsblätter“"1926, Bd. 51, S. 28-71.

Böcker H., Autonome Rechte und Entwicklungsfaktoren in Haldensleben bis zum Ende des 15. Jahrhunderts, [in:] Autonomie, Wirtschaft und Kultur der Hansestädte. Johannes Schildhauer zum 65. Geburtstag, hrsg. v. K. Fritze, E. Müller-Mertens, Weimar 1984, S. 84-93.

Bünz E., Die Aufhebung der holsteinischen Augustiner-Chorherrenstifte Bordesholm und Segeberg in der Reformationszeit, [in:] Reform - Sequestration - Säkularisation: Die Niederlassungen der Augustiner-Chorherren im Zeitalter der Reformation und am Ende des alten Reiches, hrsg. v. W. Müller, Paring 2005, S. 39-78.

Daenell E., Die Blütezeit der Deutschen Hanse, Hansische Geschichte von der zweiten Hälfte des XIV. bis zum letzten Viertel des XV. Jahrhunderts, Bd. 2, Berlin 1906.

Ebel W., Lübisches Recht, Bd. 1, Lübeck 1971.

Engel E., Zur Autonomie brandenburgischer Hansestädte im Mittelalter, [in:] Autonomie, Wirtschaft und Kultur der Hansestädte. Johannes Schildhauer zum 65. Geburtstag, hrsg. v. K. Fritze, E. Müller-Mertens, Weimar 1984, S. 45-75.

Fehring G., Lübeck zur Zeit der Welfen (1125-1235): Archäologische Erkenntnisse zu Topographie, Grundstücks- und Bebauungsstrukturen, [in:] Heinrich der Löwe und seine Zeit. Herrschaft und Repräsentation der Welfen 1125-1235. Katalog der Ausstellung Braunschweig 1995, hrsg. v. J. Lurckhardt, F. Niehoff, G. Biegel, Teilband 2, München 1995, S. 408-417.

Fritze K., Autonomie von Mittel- und Kleinstädten. Dargestellt am Beispiel der mittelalterlichen Kleinstädte Vorpommerns, [in:] Autonomie, Wirtschaft und Kultur der Hansestädte. Johannes Schildhauer zum 65. Geburtstag, hrsg. v. K. Fritze, E. Müller-Mertens, Weimar 1984, S. 76-83.

Gaethke H.-O., Knud VI. und Waldemar II. von Dänemark und Nordalbingien 1182-1227, Tl. 3, „Zeitschrift der Gesellschaft für Schleswig-Holsteinische Geschichte“ 1996, Bd. 121, S. 7-44.

Grundlagen für ein neues Europa. Das Magdeburger und Lübecker Recht in Spätmittelalter und Früher Neuzeit, hrsg. v. H. Lück, M. Puhle, A. Ranft, Köln u.a. 2009.

Hahn P.-M., Geschichte Brandenburgs, München 2009.

Hammel-Kiesow R., Die Anfänge Lübecks: Von der abotritischen Landnahme bis zur Eingliederung in die Grafschaft Holstein-Stormarn, [in:] Lübeckische Geschichte, hrsg. v. A. Graßmann, Lübeck 1988, S. 6-49.

Hammel-Kiesow R., Die Hanse, München 20145.

Hammel-Kiesow R., Pelc O., Landesausbau, Territorialherrschaft, Produktion und Handel im Hohen und Späten Mittelalter, [in:] Geschichte Schleswig-Holsteins. Von den Anfängen bis zur Gegenwart, hrsg. v. U. Lange, Neumünster 2003², S. 59-134.

Hansegeschichte als Regionalgeschichte. Beiträge einer internationalen und interdisziplinären Winterschule in Greifswald vom 20. bis 24. Februar 2012, hrsg. v. O. Auge, Frankfurt a. M. u.a. 2014.

Hardt M., Lübeck in der Zeit Arnolds, [in:] Die Chronik Arnolds von Lübeck. Neue Wege zu ihrem Verständnis, hrsg. v. S. Freund, B. Schütte, Frankfurt a. M. 2008, S. 175-190.

Hatz G., Die Anfänge des Münzwesens in Holstein. Die Prägungen der Grafen von Schauenburg bis 1325, [in:] Numismatische Studien Heft 5, hrsg. v. W. Hävernick, Hamburg 1952, S. 114-116.

Hill T., Kleine Städte in der Hanse. Das Beispiel Kiels (1250-1400), [in:] Ene vruntlike tohopesate. Beiträge zur Geschichte Pommerns, des Ostseeraumes und der Hanse. Festschrift für Horst Wernicke zum 65. Geburtstag, hrsg. v. S. Birli u.a., Hamburg 2016, S. 247-264.

Hoffmann E., Die Bedeutung der Schlacht von Bornhöved für die deutsche und skandinavische Geschichte, „Zeitschrift des Vereins für Lübeckische Geschichte und Altertumskunde“ 1977, Bd. 57, S. 9-37. 
Hoffmann E., Lübeck im Hoch- und Spätmittelalter: Die große Zeit Lübecks, [in:] Lübeckische Geschichte, hrsg. v. A. Graßmann, Lübeck 1988, S. 79-340.

Hoffmann E., Spätmittelalter und Reformationszeit, Geschichte Schleswig-Holsteins Bd. 4/2, 1.-4. Lief., Neumünster 1990, S. 66-76.

Jahnke C., Silber des Meeres. Fang und Vertrieb von Ostseehering zwischen Norwegen und Italien (12.-16. Jahrhundert), Köln u.a. 2000, S. 244-249.

Jessen C., Kiel als Mitglied der deutschen Hanse, „Zeitschrift der Gesellschaft für Schleswig-Holsteinische Geschichte“" 1882, Bd. 12, S. 131-16.

Kroeschell K., s.v. Stadtrecht, Stadtrechtsfamilien, [in:] Lexikon des Mittelalters VIII, ND München 2002, Sp. 24-26.

Laan P.H.J. van der, Die städtische Autonomie in den nördlichen Niederlanden bis zum 17. Jahrhundert, [in:] Autonomie, Wirtschaft und Kultur der Hansestädte. Johannes Schildhauer zum 65. Geburtstag, hrsg. v. K. Fritze, E. Müller-Mertens, Weimar 1984, S. 101-110.

Lammers W., Geschichte Schleswig-Holsteins, Bd. 4, 1: Das Hochmittelalter bis zur Schlacht von Bornhöved, Neumünster 1981.

Landgraf H., Bevölkerung und Wirtschaft Kiels im 15. Jahrhundert, Neumünster 1959.

Langusch S., Salzwedel und die Hanse, „Jahresbericht des altmärkischen Vereins“ 2015, Bd. 85, S. $1-39$.

Leverkus W., Berichte über die Schleswig-Holsteinischen Landtage von 1525, 1526, 1533, 1540, [in:] Archiv für Staats- und Kirchengeschichte der Herzogtümer Schleswig, Holstein, Lauenburg und der angrenzenden Länder und Städte, hrsg. v. A. Michelsen, Bd. 4, Altona 1840, S. 451-505.

Marx K., Das Kapital, Bd. 1, Berlin 1971.

Mohrmann W.-D., Der Landfriede im Ostseeraum während des späten Mittelalters, Kallmünz 1972.

Müller-Mertens E., Bürgerlich-städtische Autonomie in der Feudalgesellschaft. Begriff und geschichtliche Bedeutung, [in:] Autonomie, Wirtschaft und Kultur der Hansestädte. Johannes Schildhauer zum 65. Geburtstag, hrsg. v. K. Fritze, E. Müller-Mertens, Weimar 1984.

Pelc O., Lübeck unter der Herrschaft Waldemars II. von Dänemark, [in:] Dänen in Lübeck = Danskere i Lübeck: 1203-2003, hrsg. v. M. Gläser, D. Mührenberg, P.B. Hansen, Lübeck 2003, S. 45-50.

Pomsel E., Das Ende der Hansemitgliedschaft Kiels, „Mitteilungen der Gesellschaft für Kieler Stadtgeschichte" 1949, Bd. 45, S. 11-34.

Priebatsch F., Die Hohenzollern und die Städte in der Mark im 15. Jahrhundert, Berlin 1892.

Puhle M., Das politische System der Hansestädte, [in:] Die Hanse, hrsg. v. R. Hammel-Kiesow, M. Puhle, S. Wittenburg, Darmstadt 2009, S. 74-83.

Puhle M., Politik und Diplomatie, [in:] Die Hanse, hrsg. v. R. Hammel-Kiesow, M. Puhle, S. Wittenburg, Darmstadt 2009, S. 160-173.

Reincke H., Kaiser Karl IV. und die deutsche Hanse, Lübeck 1931.

Sarnowsky J., Das Ende der mittelalterlichen Hanse, [in:] Ene vruntlike tohopesate. Beiträge zu Geschichte Pommerns, des Ostseeraums und der Hanse: Festschrift für Horst Wernicke zum 65. Geburtstag, hrsg. v. S. Birli u.a., Hamburg 2016, S. 499-517.

Schürrer M., Die Schauenburger in Nordelbien. Die Entwicklung gräflicher Handlungsspielräume im 12. Jahrhundert, Frankfurt a. M. 2017.

Selzer S., Die mittelalterliche Hanse, Darmstadt 2010.

Springer M., Städte im Krieg: Der Kampf Magdeburgs und seiner Verbündeten gegen den Erzbischof Günther in den Jahren 1431 bis 1435, [in:] Hanse, Städte, Bünde. Die sächsischen Städte zwischen Elbe und Weser um 1500, Bd. 1: Aufsätze, hrsg. v. M. Puhle, Magdeburg 1996, S. 191-199.

Strahm H., Stadtluft macht frei, [in:] Das Problem der Freiheit in der Deutschen und Schweizerischen Geschichte, hrsg. v. Konstanzer Arbeitskreis für mittelalterliche Geschichte, Konstanz 1954, S. 103-121. 
Usinger R., Deutsch-dänische Geschichte 1189-1227, Berlin 1863.

Vollmath-Lindenthal M., Die Stellung der Bischöfe in Halberstadt im Gefüge der politischen Landschaft (1300-1500), [in:] Geschichte und Kultur des Bistums Halberstadt. 804-1648, hrsg. v. A. Siebrecht, Halberstadt 2006, S. 555-562.

Walther H.G., Von der Holstenstadt der Schauenburger zur Landesstadt des holsteinischen Adels, 1242 bis 1544, [in:] Geschichte der Stadt Kiel, hrsg. v. J. Jensen, P. Wulf, Neumünster 1991, S. $13-58$.

Wehrmann C., Die Verpfändung Kiels an Lübeck im Jahre 1469, „Zeitschrift des Vereins für lübeckische Geschichte und Altertumskunde“" 1863, Heft 2, S. 38-74.

Wehrmann M., Geschichte von Pommern. Erster Band bis zur Reformation (1525), Gotha 1904.

Wernicke H., Die Stadt in der Städtehanse. Zwischen städtischer Autonomie und bündischer Pflichterfüllung, [in:] Autonomie, Wirtschaft und Kultur der Hansestädte. Johannes Schildhauer zum 65. Geburtstag, hrsg. v. K. Fritze, E. Müller-Mertens, Weimar 1984, S. 35-44.

Weyhe L., s.v. Lübisches Recht, [in:] Lexikon des Mittelalters V, ND München 2002, Sp. $2150 \mathrm{f}$.

Wille-Jørgensen D., Das Ostseeimperium der Waldemaren: Dänische Expansion 1160-1227, [in:] Dänen in Lübeck = Danskere i Lübeck: 1203-2003, hrsg. v. M. Gläser, D. Mührenberg, P.B. Hansen, Lübeck 2003, S. 26-35.

Willert H., Anfänge und frühe Entwicklung der Städte Kiel, Oldesloe und Plön, Neumünster 1990.

Zientara B., Das Deutsche Recht (ius Teutonicum) und die Anfänge der städtischen Autonomie, [in:] Autonomie, Wirtschaft und Kultur der Hansestädte. Johannes Schildhauer zum 65. Geburtstag, hrsg. v. K. Fritze, E. Müller-Mertens, Weimar 1984, S. 94-100.

\section{SUMMARY}

The municipal law of Magdeburg profoundly influenced the genesis and development of municipal laws and, consequently, of urban development in central Eastern and Eastern Europe. The second influential group of municipal law, deeply affecting urbanisation and the establishment of autonomy in vast parts of Eastern Europe, is that of Lübeck law. Over a 100 cities, including Reval and also Novgorod, can be ascribed to this family of municipal law, which extended mostly to the Southern Baltic area and the adjacent regions. The majority of these cities considered themselves, at least for some time, Hansa cities. This contribution focuses on the struggle for autonomy between these cities and the local sovereignty. The current state of research in this regard forms the basis for analysing the genesis of urban autonomy in Lübeck and its struggle with competing urban rulers up until 1226. Then, the example of Kiel shows how other cities tried to emulate the model given by Lübeck with varying success. Finally, this contribution outlines how the Hansa cities, on their way to an intensified alliance policy, tried to make a stand against the growing pressure of territorialisation exerted by princes and local sovereigns in the late Middle Ages. Although these alliance plans did eventually fail, this must not be viewed as the end of urban autonomy. The cities did not lose their autonomy until the period of Absolutism.

Keywords: Lübeck; Lübeck law; Kiel; Autonomy; alliance policy; Absolutism; lordship; meeting ride

\section{STRESZCZENIE}

Miejskie prawo magdeburskie miało znaczący wpływ na genezę i rozwój prawa miejskiego, a w rezultacie na rozwój miast w Europie Środkowo-Wschodniej i Wschodniej. Drugą wpływową grupą prawa miejskiego, która w znacznym stopniu oddziaływała na urbanizację i ustanowienie 
autonomii na rozległych obszarach Europy Wschodniej, jest prawo lubeckie. Ponad 100 miast, w tym Rewel czy Nowogród, można przypisać do tej rodziny prawa miejskiego, które rozprzestrzeniało się głównie w rejonie południowego Bałtyku i na obszarach przyległych. Większość tych miast uważała się, przynajmniej przez pewien czas, za miasta hanzeatyckie. Tematyka artykułu dotyczy głównie walki o autonomię, jaka toczyła się między miastami a miejscową władzą. Aktualny stan badań w tym zakresie daje podstawy do analizy zagadnienia genezy autonomii miejskiej Lubeki i jej walki z rywalizującymi władcami miasta aż do 1226 r. Przykład Kilonii i innych miast pokazuje, jak - z różnym skutkiem - próbowały one naśladować wzór dany przez Lubekę. Wreszcie tekst ukazuje, jak miasta hanzeatyckie, w drodze do zintensyfikowanej polityki sojuszy, próbowały przeciwstawić się rosnącej presji terytorializacji wywieranej przez książęta i suwerenów w późnym średniowieczu. Chociaż plany sojuszy ostatecznie upadły, nie wolno tego postrzegać jako końca miejskiej autonomii. Miasta nie utraciły bowiem swojej autonomii aż do epoki absolutyzmu.

Słowa kluczowe: prawo lubeckie; Lubeka; autonomia; Kilonia; władza nad ziemią; polityka sojuszy; absolutyzm 